\title{
EXTENDING FREIGHT FLOW MODELLING TO SUB-SAHARAN AFRICA TO INFORM INFRASTRUCTURE INVESTMENTS - TRADE DATA ISSUES
}

\author{
JAN HAVENGA* \\ ZANE SIMPSON \\ DAVID KING \\ E.J. LANZ \\ LEILA GOEDHALS-GERBER \\ ANNEKE DE BOD \\ *janh@sun.ac.za \\ Department of Logistics \\ Stellenbosch University, South Africa
}

\begin{abstract}
This paper highlights the first attempt by researchers at Stellenbosch University to model freight flows between and for 17 countries in sub-Saharan Africa (SSA). The model will be informed by and linked to the South African surface Freight Demand Model (FDM) given these dimensions. By analysing and collating available datasets and developing a freight flow model, a better understanding of freight movements between countries can be obtained and then used for long-term planning efforts. A simple methodology is envisaged that will entail a high-level corridor classification that links a major district in the country with a similar district in another country. Existing trade data will be used to corroborate new base-year economic demand and supply volumetric data that will be generated from social accounting matrices for each country. The trade data will also provide initial flow dynamics between countries that will be refined according to the new volumes. The model can then generate commodity-level corridor flows between SSA countries, and between SSA countries and the rest of the world, as well as intra-country rural and metropolitan flows, using a gravity-based modelling approach. This article outlines efforts to harmonise trade data between the 17 countries identified, as well as between these countries and the rest of the world as a first step towards developing a freight demand model for sub-Saharan Africa.
\end{abstract}

\section{INTRODUCTION}

For many developing countries, especially countries in sub-Saharan Africa (SSA), integration into world markets requires a long leap forward as far as availability and quality of transport and other logistics services are concerned. For example, transport and insurance costs as a percentage of trade value are on average around 20\% for SSA landlocked countries compared to 5\% for Organisation for Economic Co-operation and Development (OECD) 
countries (De Bod, 2008). It is obvious that that being landlocked and far away from trading countries causes challenges, but at the same time this fact means even more focused management of this strategic issue (including measurement). This impacts significantly on the competitiveness of SSA exports and also on the costs of imports and, therefore, the prices of goods in the local market. A major problem faced by these countries is the lack of usable logistics information to influence governments to prioritise and invest in logistics infrastructure (physical and virtual), as well as facilitate customs and trade procedures. These governments often feel that other more pressing developmental priorities require attention, yet for SSA to achieve the 7\% GDP growth rates needed to reduce poverty, infrastructure investment requirements amount to an estimated USD20 billion per annum, twice as much as the region invested historically (World Bank, 2005). There are indications that logistics cost reduction opportunities exist through freight densification on rail (De Bod \& Havenga, 2010). This study is the first attempt to generate a uniform way in which to translate trade data into reliable freight flows for the SSA market and to initiate an understanding of trade flows in and between countries, which in turn will enable the lobbying of appropriate logistics infrastructure investments.

\section{RESEARCH STRATEGY}

The logistics infrastructure in SSA is inadequate and generally in a poor state, impeding development. This leads to costly, slow and unreliable cross-border corridor transport in most of SSA. Having a better understanding of freight flows across borders could enable the measurement of the full logistics costs of border delays. These challenges are exacerbated for landlocked countries with export potential (De Bod, 2008). In order to enable appropriate logistics infrastructure maintenance, upgrade and investment, an understanding of the current and future demand for freight transport is critical. Freight flow analysis has, however, been historically lacking due to the general lack of, and inconsistencies in, data available for SSA countries. By analysing and collating available datasets and developing a freight flow model a better understanding of freight movements between countries can be obtained and can thus be used for long-term planning efforts.

\section{Procedure}

A methodology is required that can develop corridor freight flows with reasonable confidence and an approximation of domestic freight (at least with a metropolitan and rural dimension). The model will be informed by and linked to the South African surface Freight Demand Model (FDM) given these dimensions. South Africa's FDM has been developed and refined over the past 15 years. Starting from a 19-region model, it has been refined to model freight flows between 372 districts for 71 separate commodities inside the country's borders for all transport modes, split between metropolitan, corridor, rural and bulk-mining typology levels (Havenga, 2007). The first full-scale version of the FDM was released in 
2006, and it has been updated on an annual basis since then. The 2012 model contains base-year data for 2010 and projections for 2011-2016, 2021, 2026 and 2041.

Developing a similar model to the South African FDM for each SSA country is prohibitively costly and time-consuming. Therefore a much simpler methodology (lower levels of granularity, larger regions, more focus on trans-frontier flows and less on domestic flows) will be followed, entailing a high-level corridor classification that links countries with one another. In order to achieve this, an initial translation of trade flows into commodity- and volume-based freight flows is necessary.

\section{DISCUSSION}

Extensive research into multi-country freight demand models has been conducted in Europe. A project called Strategic European Multi-Modal Modelling (STEMM) was run from March 1996 to June 1998 funded by the 4th Transport Research and Technological Development (RDT) Framework Programme (FP). Computer models were developed for passenger and freight transport to simulate mode and route choice for European networks and specific major corridors (Baxter Eadie Limited, 1999). TRANS-TOOLS ('TOOLS for Transport Forecasting and Scenario Testing') is a European transport network model that followed from the STEMM project and is co-funded by the 6th FP. It covers passenger and freight, as well as intermodal transport. It combines advanced modelling techniques in transport generation and assignment, economic activity, trade, logistics, regional development and environmental impacts (European Commission, 2008).

The SSA FDM follows a similar structure and method as the abovementioned models, but is simplified mainly due to lack of reliable data. The model is not a simulation model but a snapshot of flows between the different countries. It also concentrates on country-to-country flows and does not include magisterial districts as in the South African FDM; therefore intracountry flows will only be split between urban and rural movements, while corridor flows will only be between major economic centres in each country. For a start, the model will not be mode-specific and will therefore not distinguish between road and rail movements. An estimation of domestic flows will be added in future, based on surveys of various countries.

The first step in the research approach is to develop a database for trade between SSA countries and with the rest of the world which is covered in this paper. The trade data will be used to corroborate the base year demand (i.e. intermediate demand, consumption, investments and exports) and supply (i.e. production and imports) tables generated from social accounting matrices for each country. Five and 30-year forecasts of the supply and demand tables can then be developed as a next step, informed by macro-economic industry outlooks (i.e. the macro-economic variables of the economy disaggregated by 
Social Accounting Matrices per country and a long-term forecast) and regional investments. The final step in the model will be the generation of commodity-level corridor flows (for the base year and the forecast years) between SSA countries, and between SSA countries and the rest of the world, as well as intra-country rural and metropolitan flows, using a gravitybased modelling approach as in South Africa's FDM.

Gravity-based approaches are based on the premise that trade flows between origins and destinations are determined by measures of supply and demand, as deduced from the input-output tables for each country and a measure of transport resistance (Krygsman, 2006; Havenga, 2007). The measure of transport resistance refers to the real transport cost variable for overcoming the spatial discrepancy between supply and demand locations. For the purposes of this research, a distance decay function (the degree to which freight 'wants' to move) is used as a transport resistance measure, informed by similar research conducted for South Africa's FDM.

Seventeen SSA countries are included in the study, namely, Angola, Botswana, Burundi, Congo, Democratic Republic of Congo (DRC), Kenya, Lesotho, Malawi, Mozambique, Namibia, Rwanda, South Africa, Swaziland, Tanzania, Uganda, Zambia and Zimbabwe, focusing on the major intra-regional corridors as depicted in Figure 1.

At the outset it is critical to create a reliable platform from which to develop and forecast freight flows. The majority of work thus far has therefore been to obtain trade flows (imports and exports) between the 17 countries (intra-SSA), as well as trade flows between each of the countries and the five continental groups of Africa, America (North and South America combined), Asia, Europe and Oceania. This task was more onerous than anticipated, as described in the rest of the paper. 


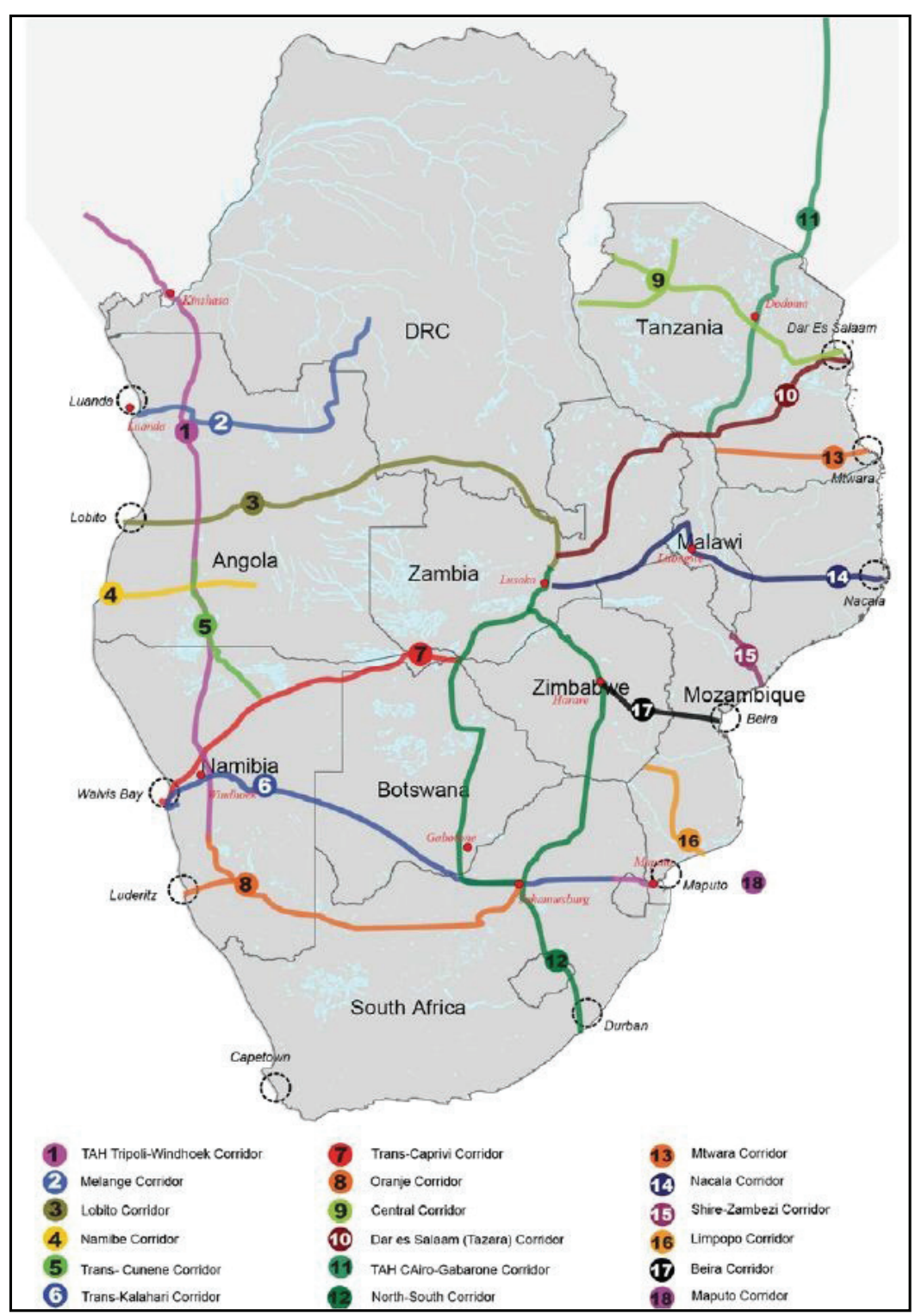

Figure 1: Major intra-regional corridors (JICA, 2010)

Trade data from two major sources were obtained and processed on the Harmonized System 4 digit (HS-4) commodity level. Both datasets use official country statistics sourced from the respective governments or trading partner. There are approximately $1400 \mathrm{HS}-4$ level commodities. Once the data were processed the commodities were consolidated into 71 commodity groups based on Standard Industry Classification (SIC) codes as per the South African FDM.

\section{Intra-SSA data}

Intra-SSA data were extracted from the UN Comtrade database (United Nations Commodity Trade Statistics Database, 2012). Of the approximately 65000 entries relating to the region, $94 \%$ had both a US dollar (USD) value and kilogram $(\mathrm{kg})$ value, with the remaining $6 \%$ of entries having only a USD value. For each HS-4 commodity the entries that had a USD and $\mathrm{kg}$ value were consolidated and used in order to obtain an average intra-SSA USD/kg value. 
This value was then used to estimate the $\mathrm{kg}$ value for the remaining $6 \%$ of entries that only had a USD value.

Botswana, Burundi, Congo, Kenya, Malawi, Mozambique, Rwanda, South Africa, Uganda, Tanzania, Zambia and Zimbabwe all had 2010 recorded data; Lesotho and Namibia had 2008 data; and Swaziland had 2007 data as the most recently recorded data. Angola and the DRC did not have any recorded data in the UN Comtrade database. For countries whose data was not from 2010, kg values were kept the same but the USD value was inflated by the Consumer Price Index (CPI) of the specific country over the period up to 2010 (Trading Economics, 2012). All kg values were converted to metric tonne ( $t$ ) values.

A data entry is reported by a country as an import from or export to another country. Each data entry has a mirrored data entry (i.e. commodity 1 reported by Country $A$ as an export to Country $B$ is mirrored by commodity 1 reported by Country $B$ as an import from Country A). Major discrepancies were found in some of the data values and to overcome this it was decided that in all cases the maximum value reported will be used. The reason for taking the maximum is that an average value could distort both entries and if the minimum value was taken some flows would have been meaningless. To guard against over-estimation desktop research was conducted for commodities with extreme values to obtain a sound volumetric figure. This was however not possible for all cases and could be improved in future iterations.

\section{World-SSA data}

World-SSA data were extracted from the ITC Trade Map database (International Trade Centre Trade Map, 2012) on a regional group level. The data consist of imports and exports reported to and from the 17 SSA countries to the five continental groups (Africa, America, Asia, Europe and Oceania). The data extracted were USD values for the five-year period 2006-2010. The country-specific average USD/kg value for each HS-4 level commodity obtained from the intra-SSA data was used to calculate tonnage values. If no country-specific average USD/kg value was available then the intra-SSA average USD/kg value was used.

Botswana, Burundi, Kenya, Malawi, Mozambique, Rwanda, South Africa, Uganda, Tanzania, Zambia and Zimbabwe all had 2010 recorded data, while Namibia had 2008 and Swaziland had 2007 data as the most recently recorded data. Angola, Congo, DRC and Lesotho did not have recorded data in the ITC Trade Map database. For country data prior to 2010, the USD value was inflated by the CPI of the given country over the period to 2010 (Trading Economics, 2012). All kilogram values were converted to metric tonne (t) values.

To check the validity of the intra-SSA USD/tonne values, the intra-SSA USD/tonne value for the HS-4 commodity was compared to ITC Trade Map trade indicator data. These data give 
the import and export USD value and if available a quantity value (in tonnes) and a USD/ tonne rate, for a given country or group of countries.

The intra-SSA USD/tonne values were not always consistent or usable and therefore these variables were then updated applying one of the following options:

- the seventeen SSA country average USD/tonne rate

- the world average rate

- the South African rate

- a rate from a top sub-Saharan trader in the given commodity

- an average rate of a combination of the options

The option used was based on the availability of data and an attempt to preserve tonne volumes for the sub-Saharan region. As a next step these results will be tested in field research.

Given the volume of data, a phased update approach was used. The first update was done on the top $100 \mathrm{HS}-4$ level commodities (based on total tonnes). The second update was done by following the same procedure on a further $127 \mathrm{HS}-4$ level commodities. The third update was done for each separate country on the top ten (or commodities exceeding 100 000 tonnes). For this update the USD/t rate for the given country from the trade indicators was used. South Africa has the largest share of sub-Saharan trade, therefore any of the 227 commodities (checked in the first two phases) that had available USD/t values were updated. After the three updates the top $170 \mathrm{HS}-4$ level commodities had been updated (based on total tonnes), resulting in approximately $94 \%$ of the total tonnes checked and updated where required.

\section{Research results}

\section{Comparison of SSA FDM commodity rates with South African FDM commodity rates}

Table 1 gives a comparison between the commodity prices used in the South African FDM and the prices derived from the UN Comtrade and ITC Trade Map databases. 
Extending Freight Flow Modelling to Sub-Saharan Africa to

Inform Infrastructure Investments - Trade Data Issues

Table 1: Comparison of SSA FDM commodity rates with South African FDM commodity rates

\begin{tabular}{|c|c|c|c|c|c|}
\hline \multirow{3}{*}{ Commodity } & \multicolumn{5}{|c|}{ Commodity prices (USD / Tonne) } \\
\hline & \multicolumn{2}{|c|}{ South African FDM } & \multicolumn{3}{|c|}{ Sub-Saharan African FDM } \\
\hline & Exports & Imports & From SSA (export) & From World (Import) & Intra SSA \\
\hline \begin{tabular}{l|l|} 
BARLEY \\
\end{tabular} & 295 & 322 & 669 & 671 & 670 \\
\hline 2 COTTON & 267 & 520 & 1,652 & 1,709 & 1,587 \\
\hline \begin{tabular}{l|l}
3 & DECIDUOUS FRUIT \\
\end{tabular} & 991 & 565 & 1,180 & 1,060 & 736 \\
\hline \begin{tabular}{|l|l|}
4 & CITRUS \\
\end{tabular} & 441 & 439 & 604 & 819 & 31 \\
\hline \begin{tabular}{l|l}
5 & SUBTROPICAL FRUIT \\
\end{tabular} & 749 & 679 & 502 & 293 & 315 \\
\hline \begin{tabular}{l|l}
6 & VITICULTURE \\
\end{tabular} & 351 & 351 & - & - & \\
\hline $\begin{array}{ll}\text { GRAIN SORGHUM } \\
\end{array}$ & 177 & 208 & 288 & 197 & 308 \\
\hline 8 LIVESTOCK (SLAUGHTERED) & 3,910 & 3,839 & 3,628 & 2,200 & 3,334 \\
\hline 9 MAIZE & 158 & 173 & 262 & 335 & 147 \\
\hline \begin{tabular}{|l|l|}
10 & SOYA BEANS \\
\end{tabular} & 362 & 374 & 423 & 408 & 401 \\
\hline \begin{tabular}{|l|l|}
11 SUNFLOWER SEED \\
\end{tabular} & 414 & 414 & 489 & 417 & 458 \\
\hline \begin{tabular}{c|c}
12 & VEGETABLES \\
\end{tabular} & 392 & 423 & 811 & 650 & 473 \\
\hline \begin{tabular}{l|l|}
13 & WHEAT \\
\end{tabular} & 275 & 249 & 324 & 279 & 225 \\
\hline \begin{tabular}{c|c|}
14 & POULTRY PRODUCTS \\
\end{tabular} & 1,969 & 1,962 & 2,049 & 1,085 & 1,667 \\
\hline \begin{tabular}{l|l|l|}
$15 A I R Y$ \\
\end{tabular} & 446 & 446 & 924 & 806 & 899 \\
\hline \begin{tabular}{l|l|}
16 & SUGAR CANE \\
\end{tabular} & 37 & 37 & 554 & 599 & 461 \\
\hline \begin{tabular}{l|l}
17 & OTHER AGRICULTURE \\
\end{tabular} & 244 & 202 & 2,945 & 3,093 & 876 \\
\hline \begin{tabular}{l|l|}
18 & COAL MINING: EXPORTS \\
\end{tabular} & 76 & 26 & 80 & 229 & 94 \\
\hline \begin{tabular}{c|c|}
19 & CRUDE PETROLEUM \& NATURAL GAS \\
\end{tabular} & 458 & 514 & 562 & 540 & 401 \\
\hline $20 \mid$ IRON ORE: EXPORTS & 84 & 110 & 111 & 138 & 102 \\
\hline \begin{tabular}{l|l|l|}
21 & MAGNETITE \\
\end{tabular} & 75 & 64 & - & -9 & - \\
\hline \begin{tabular}{l|l|}
22 & CHROME \\
\end{tabular} & 114 & 78 & 226 & 137 & 105 \\
\hline \begin{tabular}{l|l|}
23 & COPPER \\
\end{tabular} & 6,760 & 7,065 & 2,714 & 2,008 & 2,342 \\
\hline \begin{tabular}{l|l|}
24 & MANGANESE: EXPORTS \\
\end{tabular} & 152 & 204 & 218 & 219 & 205 \\
\hline \begin{tabular}{l|l|l|}
25 & TITANIUM \\
\end{tabular} & 543 & 642 & 531,250 & 537,024 & 531,250 \\
\hline \begin{tabular}{l|l|}
26 ZINC \\
\end{tabular} & 1,505 & 1,408 & 2,306 & 1,573 & 1,313 \\
\hline \begin{tabular}{l|l}
27 & OTHER NON-FERROUS METAL MINING \\
\end{tabular} & 760 & 892 & 1,913 & 3,336 & 4,062 \\
\hline \begin{tabular}{l|l}
28 & STONE QUARRYING, CLAY \& SAND-PITS: GRANITE \\
\end{tabular} & 186 & 226 & 179 & 130 & 195 \\
\hline \begin{tabular}{l|l}
29 & STONE QUARRYING, CLAY \& SAND-PITS: LIMESTONE \& LIME WORKS
\end{tabular} & 13 & 13 & 172 & 146 & 165 \\
\hline \begin{tabular}{l|l}
30 & STONE QUARRYING, CLAY \& SAND-PITS: OTHER \\
\end{tabular} & 10 & 7 & 295 & 429 & 238 \\
\hline \begin{tabular}{l|l|l|}
31 & MINING OF CHEMICAL \& FERTILIZER MINERALS \\
\end{tabular} & 137 & 217 & 143 & 114 & 153 \\
\hline \begin{tabular}{l|l}
32 & OTHER NON-METALLIC MINERALS \\
\end{tabular} & 268 & 268 & 160 & 108 & 85 \\
\hline \begin{tabular}{l|l|l|l|l}
33 & OTHER MINING \\
\end{tabular} & 204 & 432 & 485 & 376 & 433 \\
\hline \begin{tabular}{l|l|l|l}
34 & FOOD AND FOOD PROCESSING \\
\end{tabular} & 935 & 839 & 1,234 & 865 & 677 \\
\hline \begin{tabular}{l|l|l}
$35 E V E R A G E S$ \\
\end{tabular} & 1,294 & 1,076 & 1,354 & 1,567 & 948 \\
\hline \begin{tabular}{l|l|l|}
36 & TOBACCO PRODUCTS \\
\end{tabular} & 2,413 & 3,643 & 8,629 & 7,559 & 9,112 \\
\hline \begin{tabular}{l|l|l|}
37 & TEXTILES, CLOTHING, LEATHER PRODUCTS AND FOOTWEAR \\
\end{tabular} & 8,132 & 5,730 & 3,150 & 3,758 & 3,559 \\
\hline \begin{tabular}{l|l|l|}
38 & WOOD AND WOOD PRODUCTS \\
\end{tabular} & 310 & 654 & 245 & 721 & 310 \\
\hline \begin{tabular}{ll|l|l|l|l}
39 & FURNITURE \\
\end{tabular} & 3,726 & 3,930 & 4,782 & 3,154 & 4,276 \\
\hline \begin{tabular}{l|l|}
40 & PAPER \& PAPER PRODUCTS \\
\end{tabular} & 1,564 & 1,081 & 790 & 1,200 & 531 \\
\hline \begin{tabular}{l|l|l|} 
PRINTING AND PUBLISHING \\
\end{tabular} & 8,946 & 11,254 & 13,832 & 10,185 & 24,370 \\
\hline \begin{tabular}{l|l|}
42 & INDUSTRIAL CHEMICALS \\
\end{tabular} & 881 & 637 & 779 & 442 & 494 \\
\hline \begin{tabular}{l|l|l|}
43 & FERTILIZERS AND PESTICIDES \\
\end{tabular} & 618 & 450 & 563 & 450 & 575 \\
\hline 44 PHARMACEUTICAL, DETERGENTS AND TOILETRIES & 15,969 & 15,943 & 3,461 & 6,642 & 3,092 \\
\hline \begin{tabular}{l|l}
45 & PETROLEUM REFINERIES AND PRODUCTS OF PETROLEUM/COAL \\
\end{tabular} & 595 & 699 & 653 & $\frac{745}{745}$ & 778 \\
\hline 46 RUBBER PRODUCTS & 5,227 & 5,171 & 3,451 & 3,384 & 4,206 \\
\hline \begin{tabular}{l|l|}
47 & OTHER CHEMICALS \\
\end{tabular} & 1,119 & 1,227 & 1,760 & 2,610 & 1,206 \\
\hline \begin{tabular}{l|l|}
48 & NON-METALLIC MINERAL PRODUCTS \\
\end{tabular} & 872 & 441 & 1,853 & 995 & 793 \\
\hline \begin{tabular}{l|l|l|l|l} 
BRICKS \\
\end{tabular} & 157 & 200 & 1,078 & 1,161 & 370 \\
\hline \begin{tabular}{l|l}
50 & CEMENT \\
\end{tabular} & 263 & 144 & 117 & 92 & 139 \\
\hline 51/FERROCHROME & 793 & 793 & - & - & - \\
\hline \begin{tabular}{l|l|l|}
52 & FERROMANGANESE \\
\end{tabular} & 1,356 & 1,064 & - & - & - \\
\hline \begin{tabular}{|l|l|}
53 & OTHER IRON AND STEEL BASIC INDUSTRIES \\
\end{tabular} & 1,872 & 1,243 & 1,016 & 1,360 & 890 \\
\hline \begin{tabular}{l|l|}
54 & NON-FERROUS METAL BASIC INDUSTRIES \\
\end{tabular} & 2,203 & 3,365 & 2,826 & 2,971 & 4,254 \\
\hline \begin{tabular}{c|c|}
55 & METAL PRODUCTS EXCLUDING MACHINERY \\
\end{tabular} & 7,005 & 7,528 & 3,489 & 3,642 & 3,632 \\
\hline \begin{tabular}{|l|l|}
56 & MACHINERY AND EQUIPMENT \\
\end{tabular} & 18,242 & 12,807 & 12,631 & 8,052 & 7,641 \\
\hline \begin{tabular}{l|l}
57 & ELECTRICAL MACHINERY \\
\end{tabular} & 16,075 & 16,595 & 10,029 & 11,127 & 948 \\
\hline \begin{tabular}{l|l|}
58 & MOTOR VEHICLES \\
\end{tabular} & 12,540 & 14,280 & 8,957 & 5,532 & 6,041 \\
\hline \begin{tabular}{|l|l|}
59 & MOTOR VEHICLE PARTS AND ACCESSORIES \\
\end{tabular} & 11,175 & 12,970 & 7,469 & 6,138 & 2,561 \\
\hline \begin{tabular}{l|l|}
60 & TRANSPORT EQUIPMENT \\
\end{tabular} & 14,698 & 18,814 & 8,627 & 15,837 & 8,666 \\
\hline \begin{tabular}{l|l}
61 & OTHER MANUFACTURING INDUSTRIES \\
\end{tabular} & 10,031 & 2,821 & 10,144 & 9,910 & 9,553 \\
\hline \begin{tabular}{l|l}
62 & WATER SUPPLY \\
\end{tabular} & 85 & 100 & - & - & - \\
\hline \begin{tabular}{|l|l|}
63 & GAS \\
\end{tabular} & 821 & 831 & - & - & - \\
\hline \begin{tabular}{l|l}
64 & JETFUEL \\
\end{tabular} & 821 & 963 & - & - & - \\
\hline \begin{tabular}{c|c}
65 & COAL MINING: DOMESTIC \\
\end{tabular} & 18 & 131 & 80 & 229 & 94 \\
\hline \begin{tabular}{c|c|}
66 & COAL MINING: POWERSTATION \\
\end{tabular} & 18 & 18 & - & - & - \\
\hline \begin{tabular}{l|l}
67 & COAL MINING: SASOL \\
\end{tabular} & 18 & 18 & - & - & - \\
\hline \begin{tabular}{r|c|}
68 & COAL MINING: FLY ASH \\
\end{tabular} & 7 & 7 & - & - & - \\
\hline \begin{tabular}{l|l}
69 & IRON ORE: DOMESTIC \\
\end{tabular} & 48 & 18 & 111 & 138 & 102 \\
\hline \begin{tabular}{l|l|}
70 & MANGANESE: DOMESTIC \\
\end{tabular} & 147 & 204 & 218 & 219 & 205 \\
\hline 71|PRECIOUS METALS MINING & $27,770,359$ & $39,084,370$ & 229,981 & 165,556 & 867,349 \\
\hline
\end{tabular}


The discrepancies in the prices used in the South African FDM and the prices derived from the UN Comtrade and ITC Trade Map databases are as a result of the following issues:

- The supply and demand of a commodity is different between South Africa and the 17 SSA countries resulting in an increased or decreased USD/t price.

- The SSA countries may trade a higher or lower quality grade of commodity than South Africa resulting in an increased or decreased USD/t price.

- Some of the 71 commodities have a very large number of HS-4 level commodities which make up that commodity. The different compositions of the HS-4 level commodities between South Africa and the 17 SSA countries affect the USD/t prices.

- Prices can vary significantly between different HS-4 level commodities which form part of the same 71 commodity category.

- If the price was calculated from a very small number of data entries the value can be distorted.

Examples of these distortions include:

- Titanium, commodity number 25 , had very few HS-4 level UN Comtrade data entries and very small volumes resulting in a distorted USD/t price.

- Electrical machinery, commodity number 57, has differences in quality resulting in differences in price. The assumption is that more high-end products are traded by South Africa than traded within other SSA countries.

- The commodities magnetite (21), ferrochrome (51) and ferromanganese (52) are commodities that are grouped under another 71 commodity and a refinement of the HS-4 classification is necessary to bring them into line with the South African FDM classification.

\section{Comparing intra-SSA commodity trade data with trade to the rest of the world}

From the UN Comtrade data, intra-sub-Saharan trade flow was calculated as 49 million tonnes. The figure of 49 million tonnes seems low (less than $5 \%$ of South Africa's overland freight) but expected within the context:

- South Africa's GDP comprises $55 \%$ of the total.

- The second largest GDP observation is that of Angola, which is almost entirely driven by oil, with very little transport demand.

- A large portion of South Africa's volumes is a result of 150 million tonnes of coal and iron ore export, with a low yield of GDP, compared to transport demand.

- South Africa's GDP per capita is much higher than the rest, resulting in higher transport demand due to specialisation.

South Africa is the largest importer (25\% of imports) and exporter ( $47 \%$ of exports). Of the total tonnes, $15 \%$ was attributable to the agricultural sector, $28 \%$ to the mining sector and $56 \%$ to the manufacturing sector, creating a $44 \%-56 \%$ primary/secondary sector split. 
From the Trade Map data, trade between the world and the 17 sub-Saharan countries was calculated as 461 million tonnes with 328 million tonnes exported and 132 million tonnes imported. South Africa is the largest importer (44\% of imports) and exporter (58\% of exports). Of the exported tonnes, $3 \%$ was from the agricultural sector, $81 \%$ the mining sector and $16 \%$ the manufacturing sector. Of the imported tonnes $9 \%$ was agricultural, $28 \%$ mining and $63 \%$ manufacturing sector. This is to be expected as, in general, Africa is rich in mineral resources but lacks a well-developed manufacturing sector.

Figure 2 compares the top ten commodity split for intra-trade between the 17 countries and the top ten commodities traded with the world. It is evident that SSA relies heavily on primary commodities for its livelihood.
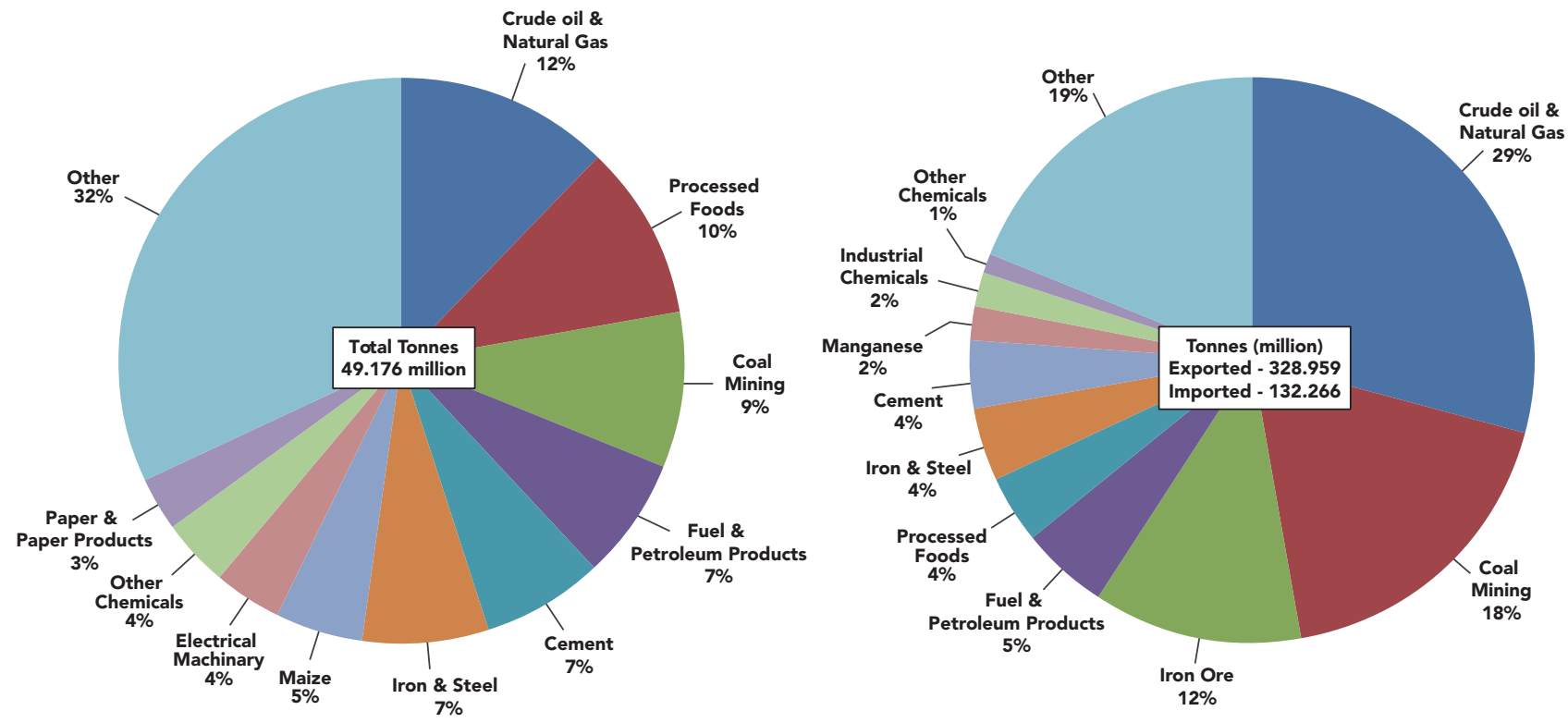

Figure 2: Comparison of commodities traded (percentage split)

Despite the verifications done on the USD/kg conversion values, there are still some data discrepancies that need to be solved. Trade between Africa and SSA should be larger than the intra-SSA flows, as intra-SSA trade are included in Africa trade. This is however not the case. The intra-SSA data (from UN Comtrade) shows imports and exports of 49 million tonnes. Trade from Africa according to the ITC Trade Map is 40.5 million and to Africa only 37 million. The difference could be as a result of intra-SSA flows being gathered from data with actual reported tonne values and the world trade from data with USD values from which the tonne values were calculated using USD/t rates. Therefore a fourth update of dollar per tonne value should be performed on the top intra-SSA commodities that do not yet have updated dollar per tonne values in the world-SSA data. 


\section{South Africa's dominant trade position in SSA}

Figure 3 shows the import and export volumes for each of the 17 countries. South Africa is responsible for $25 \%$ of imports and almost half the total exports in the intra-country trade data. A similar picture presents itself when looking at trade with the rest of the world - South Africa is responsible for $58 \%$ of all exported tonnes and receives $44 \%$ of imported tonnes.

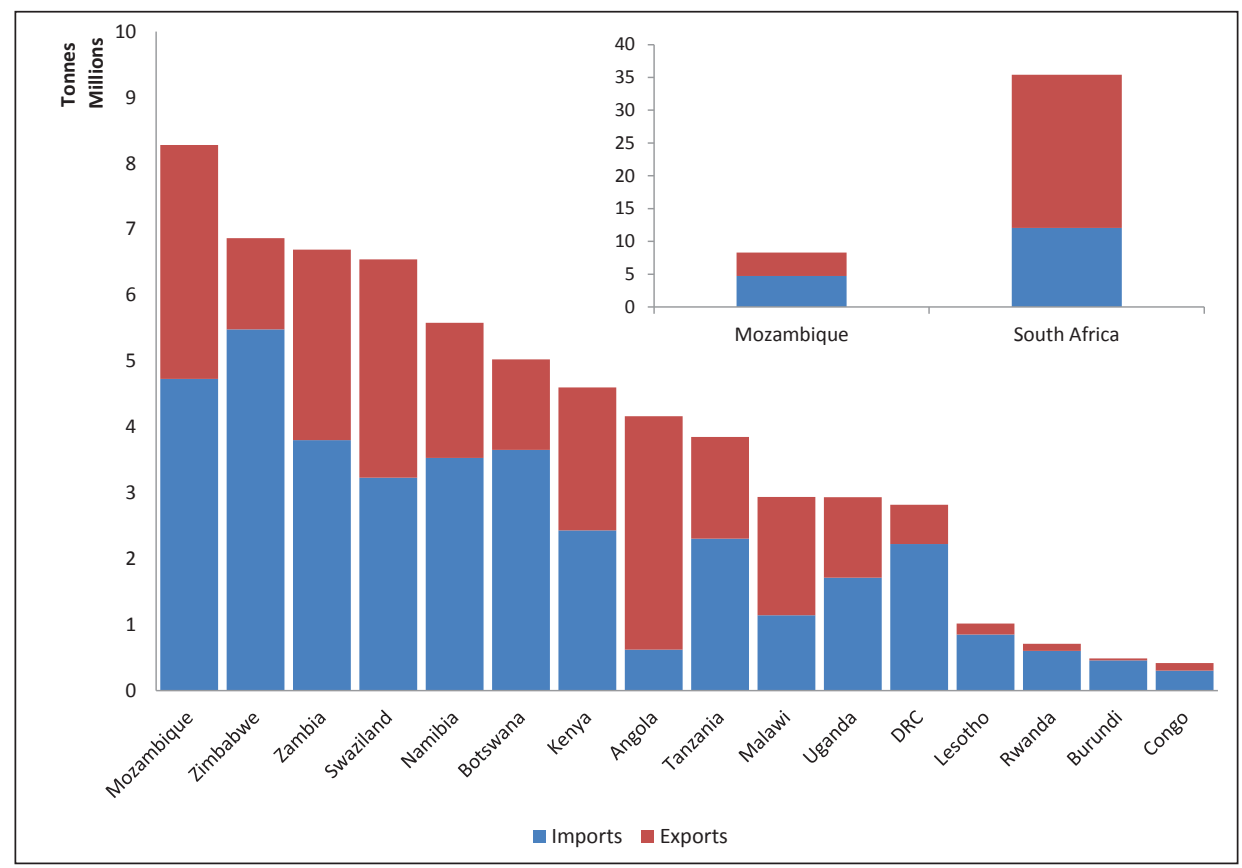

Figure 3: Comparing intra-SSA trade volumes for 2010

Figure 4 shows the export volumes per country to the five continental groups and Figure 5 the import volumes from the continental groups.

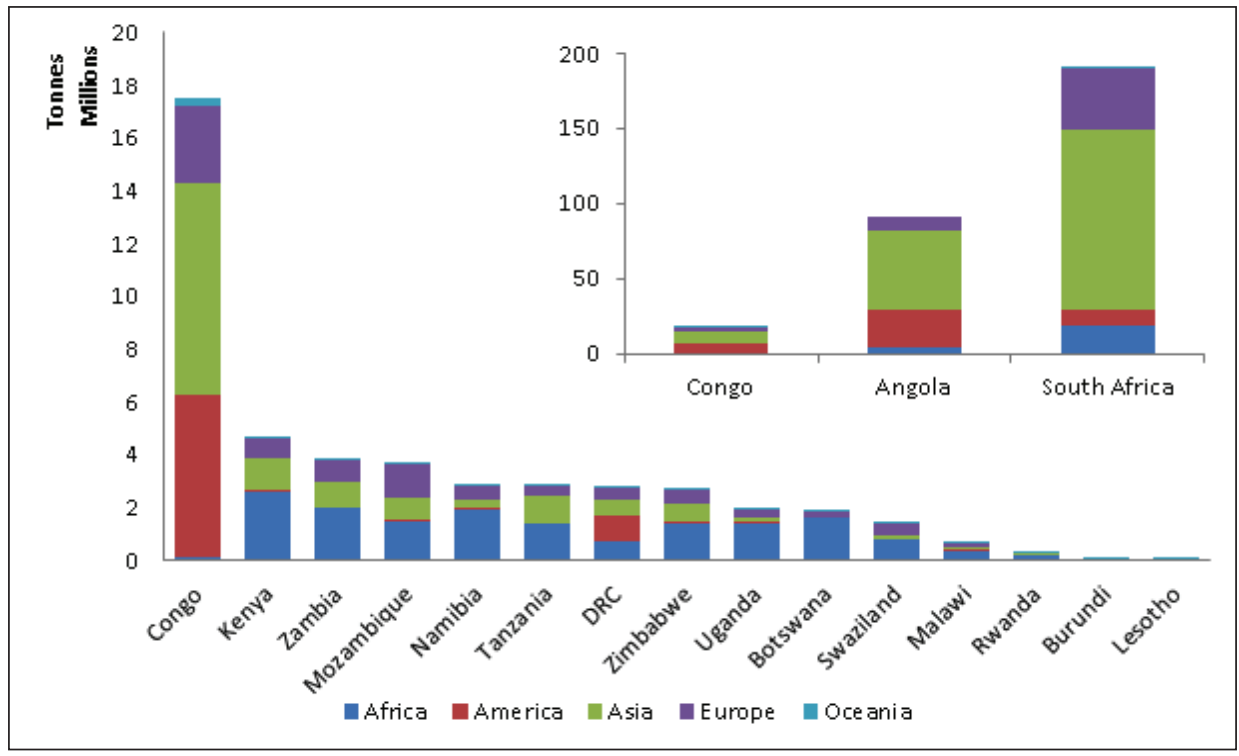

Figure 4: Export volumes to the five continental groups for 2010 


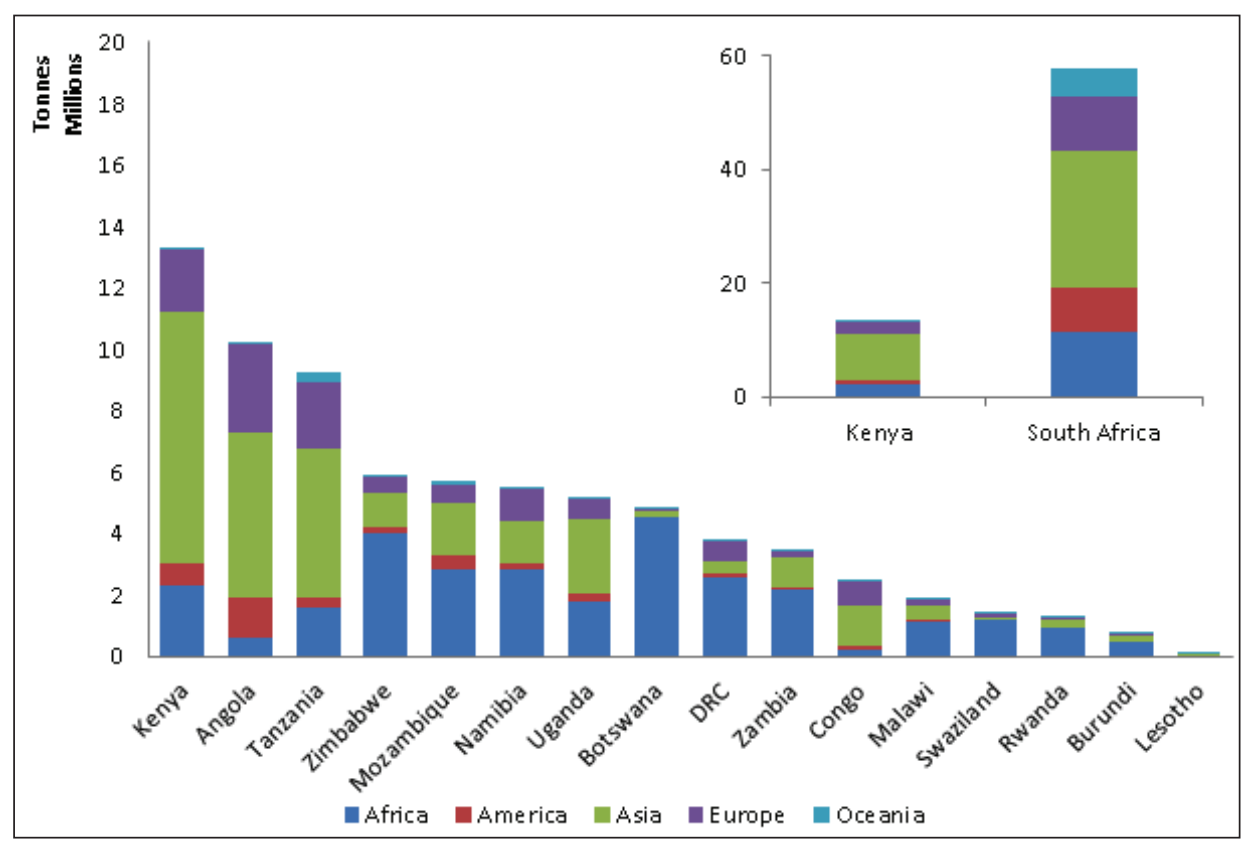

Figure 5: Import volumes from the five continental groups for 2010

Some observations from the data:

- Angola and Congo have large exports due to their crude oil production. Crude oil represents over $95 \%$ and $90 \%$ of exports for Angola and Congo respectively.

- Landlocked countries have on average lower export volumes than the coastal countries. In part this could be attributed to reporting errors in the data - commodities produced in a landlocked country get attributed to the exports of the coastal country it is exported from.

- Asia receives $57 \%$ of exported tonnes and provides $40 \%$ of imported tonnes for these 17 countries.

\section{Analysis}

The results of the trade analysis confirm some well-known challenges in the region. IntraSSA trade seems to be much more diversified than trade with the rest of the world, which is dominated by mining exports and manufacturing imports. This considerable dependence on primary commodity exports exposes the region to external shocks (such as the volatile oil price) and makes economic diversification a top priority for growth policies on the continent (UNECA, 2007). It also raises questions about the success of the myriad trade agreements between Africa and the developed world. For example, the European Union (EU) secured at least one agreement in each regional configuration in Africa, with more in some, but did not necessarily include all members of the regional configuration in the agreements (AttaMensah, 2008). 
Low intra-SSA trade compared to trade with the rest of the world points to the fact that regional integration is also not making progress (Havenga, 2011). Despite its regional dominance, South Africa's own freight logistics challenges (Havenga, 2010 and 2011) dilute its regional efforts. A concerted effort is currently being made by major role-players in South Africa, such as Transnet, to develop a cohesive approach to the region.

\section{CONCLUSIONS}

The task of developing freight flow data for SSA is a critical, but challenging, one. The development of a verified trade database for the region was the crucial first step to enable translation into reliable freight flows and is nearing completion. The remaining discrepancies between the UN Comtrade and ITC Trade Map data is currently being addressed, which will be followed by the development of base year (2010) demand and supply tables generated from social accounting matrices for each country. The trade data, however, already confirm strategic logistics challenges that are already on the regional agenda. A response to these issues should be developed in parallel with the development of the FDM to fast-track investment decisions once data-led location decisions can be made. 


\section{REFERENCES}

Atta-Mensah, J. 2008. Economic partnership agreements: regional integration in Africa, the rationalization of RECs and economic partnership agreements. Addis Ababa: UN Economic Commission for Africa.

Baxter Eadie Limited. 1999. STEMM - Final Summary Report [Online]. Available: http:// cordis.europa.eu/transport/src/stemmrep.htm [2012, May 18].

De Bod, A. 2008. South Africa's freight transport involvement options in Sub-Saharan Africa: Declining infrastructure and regulatory constraints. Unpublished Master's thesis. Stellenbosch: University of Stellenbosch.

De Bod, A. \& Havenga, J.H. 2010. Sub-Saharan Africa's rail freight transport system: Potential impact of densification on cost. Journal of Transport and Supply Chain Management, November 2010: 89-101.

European Commission [Online]. 2008. Joint Research Centre, Institute for Prospective Technological Studies, Seville, Spain. Available: http://energy.jrc.ec.europa.eu/transtools/ index.html [2012, June 14].

Havenga, J.H. 2007. The development and application of a freight transport model for South Africa. Published doctoral dissertation. Stellenbosch: Stellenbosch University.

Havenga, J.H. 2010. Logistics costs in South Africa - The case for macroeconomic measurement. South African Journal of Economics, 78(4): 460-78.

Havenga, J.H. 2011. Trade facilitation through logistics performance: The enabling role of national government. Journal of Transport and Supply Chain Management 5(1): 123-48.

International Trade Centre Trade Map [Online]. 2012. Available: http://www.trademap.org [2012, June 3].

JICA (Japan International Cooperation Agency). 2010. Preparatory Survey for Southern Africa Integrated Regional Transport Program Report. March 2010. PADECO Co., Ltd. Mitsubishi UFJ Research and Consulting Co., Ltd.

Krygsman, S. 2006. Project notes for Transnet's commodity flow project. Stellenbosch: Department of Logistics, University of Stellenbosch. 
Trading Economics [Online]. 2012. Available: http://www.tradingeconomics.com [2012, June 3].

UNECA. 2007. Economic Report on Africa 2007: Accelerating Africa's Development through Diversification. Part 1: Recent Economic Trends and Prospects for 2007 [Online]. Available at: http://www.uneca.org/eca_resources/Publications/books/era2007/chap1.pdf [2012, May 18].

United Nations Commodity Trade Statistics Database [Online]. 2012. Available: http:// comtrade.un.org/db/ [2012, June 3]

World Bank. 2005. Meeting the Challenges of Africa's Development: A World Bank Group Action Plan [Online]. Available at: http://siteresources.worldbank.org/INTAFRICA/ Resources/aap_final.pdf [2012, May 21]

\section{Table of acronyms}

\begin{tabular}{|l|l|}
\hline CPI & Consumer Price Index \\
\hline DRC & Democratic Republic of Congo \\
\hline EU & European Union \\
\hline FDM & Freight Demand Model \\
\hline FP & Framework Programme \\
\hline HS-4 & Harmonized System 4 digit \\
\hline ITC & International Trade Centre \\
\hline OECD & Organisation for Economic Co-operation and Development \\
\hline RDT & Research and Technological Development \\
\hline SIC & Standard Industry Classification \\
\hline SSA & Sub-Saharan Africa \\
\hline STEMM & Strategic European Multi-Modal Modelling \\
\hline
\end{tabular}

